\title{
Impact of a Brief Faculty Training to Improve Patient-Centered Communication while Using Electronic Health Records
}

Running Title: Faculty Training on Patient-Centered EHR Use

Wei Wei Lee, MD, MPH ${ }^{a}$, Maria L. Alkureishi, MD, FAAPb, J. Harry Isaacson, MD $^{c}$, Mark Mayer, $\mathrm{MD}^{\mathrm{d}}$, Richard M. Frankel, $\mathrm{PhD}^{\mathrm{e}}$, Daniel A. London, MD, MS ${ }^{f}$, Kristen E. Wroblewski, MS ${ }^{\mathrm{g}}$, Vineet M. Arora, MD, MAPPh

aDepartment of Medicine, University of Chicago, Chicago, USA

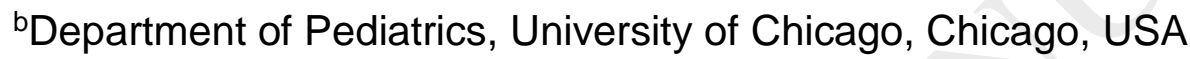

'Department of Medicine, Cleveland Clinic Lerner College of Medicine, Cleveland, USA

dDepartment of Medicine, Cleveland Clinic Lerner College of Medicine, Cleveland, USA

eDepartment of Medicine, Indiana University School of Medicine, Indianapolis, USA

fDepartment of Orthopedics, Mount Sinai Hospital System, New York, USA

9Department of Public Health Sciences, University of Chicago, Chicago USA

hDepartment of Medicine, University of Chicago, Chicago, USA

Corresponding Author:

Wei Wei Lee

University of Chicago

Department of Medicine

5841 S Maryland Avenue, MC 3051

Chicago, IL 60637 USA

Wlee6@uchicago.edu

Office phone: $773-834-8435$

Office fax: 773-834-9327

Manuscript Word Count: 3339/4000, character count 18756

Abstract Word Count: 200 
References: 39; Tables: 2; Figures: 0; Appendices: 1

\section{Highlights}

- Few faculty are trained on patient-centered communication skills while using EHRs.

- A short lecture and OSCE is a feasible and effective way to train busy faculty.

- A positive impact on physician clinic room behavior was observed post-training.

- Faculty retained the patient-centered EHR use skills three months posttraining.

\section{Abstract}

Objective: Despite rapid EHR adoption, few faculty receive training in how to implement patient-centered communication skills while using computers in exam rooms. We piloted a patient-centered EHR use training to address this issue.

Methods: Faculty received four hours of training at Cleveland Clinic and a condensed 90-minute version at the University of Chicago. Both included a lecture and a GroupObjective Structured Clinical Exam (GOSCE) experience. Direct observations of 10 faculty in their clinical practices were performed pre- and post-workshop.

Results: Thirty participants (94\%) completed a post-workshop evaluation assessing knowledge, attitude, and skills. Faculty reported that training was important, relevant, and should be required for all providers; no differences were found between longer versus shorter training. Participants in the longer training reported higher GOSCE efficacy, however shorter workshop participants agreed more with the statement that they had gained new knowledge. Faculty improved their patient-centered EHR use 
skills in clinical practice on post- versus pre-workshop ratings using a validated direct-observation rating tool.

Conclusion: A brief lecture and GOSCE can be effective in training busy faculty on patient-centered EHR use skills.

Practice Implications: Faculty training on patient-centered EHR skills can enhance patient-doctor communication and promotes positive role modeling of these skills to learners.

Key Words: Electronic Health Records, patient-centered care, communication skills, faculty development, continuing medical education

\section{Introduction}

As clinicians increasingly integrate Electronic Health Records (EHRs) into clinical practice, it is important to consider the impact of EHR use on patientdoctor communication. While benefits of computerization in health care are well described, important drawbacks exist [1]. Some studies found that EHR use can prevent doctors from focusing on patients, impede communication, and be detrimental to the patient-doctor communication [2-5]. When providers use the EHR, negative behaviors such as poor eye contact, prolonged screen gazing, and typing during sensitive discussions can emerge and have been found to undermine the patient-doctor relationship [6-7]. 
In the digital age, physicians need to be mindful of their "computer-side manner" as they adapt to accommodate the computer as the third party in the room. The reality of this situation is that physicians are managing competing demands as they try to remain focused on the patient while attending to the demands of the EHR. A recent study found that physicians spend $53 \%$ of their time on direct face to face care and $37 \%$ on EHR work and documentation while in the exam room [8]. One proposed strategy to address this issue of "distracted doctoring" is to integrate scribes or team based documentation assistants (e.g. Medical Assistants with expanded roles) into the clinical care team. While these interventions have shown promise for improving patient-doctor communication by minimizing EHR distraction, hiring scribes or expanding the role of existing team members may not be financially or logistically feasible for resource-tight academic practices [9-11]. In addition, other studies have looked at strategies to improve patient-doctor-EHR communication through enhanced exam room layouts, workflow improvements, and the use of decision aids, all with mixed results [12-13].

An alternate approach to improve patient-doctor-EHR communication may be to train physicians to utilize patient-centered communication skills. Studies have found that implementing patient-centered communication strategies can improve patient satisfaction and understanding, in addition to adherence to treatment and cost utilization [14]. Integrating patient-centered strategies may allow the EHR to be used as a tool to engage patients in meaningful discussions, enhance the therapeutic relationship and positively impact patient outcomes [15- 
18]. Several communication behaviors have been found to promote patientcentered communication when EHRs are used in the exam room. Specific behaviors include: screen sharing; starting the visit technology free; maximizing eye contact; disengaging with the EHR during sensitive discussions, and using the EHR for patient education and shared decision making [16,19-27]. In recent years, medical educators have called for curricula to teach these EHR-related communication skills and some have emerged for students and residents [28-30].

Despite the existence of best practices and calls for enhanced training on this topic, few faculty receive formal training on these key patient-centered EHR communication behaviors. As a result, they may be ill equipped to teach trainees [19-20, 23, 29, 31-33]. To address this gap an, we piloted a Patient-Centered EHR Use training for primary care faculty at two academic institutions: The University of Chicago (UC) and The Cleveland Clinic (CC).

2. Methods

\subsection{Setting and Participants}

General Internal Medicine and Family Medicine Faculty with student and/or resident precepting responsibilities were invited via email to participate in this optional training at both the Cleveland Clinic and at the University of Chicago.

\subsubsection{Cleveland Clinic}

Cleveland Clinic faculty who precept medical students in clinics participate in regular Continuing Medical Education (CME) supported faculty development sessions. The authors secured one of these sessions for the workshop and targeted Family Medicine 
and General Internal Medicine (GIM) preceptors. The 4-hour training was held in a conference room using laptops and included a 75 minute lecture and 100 minute Group Objective Structured Clinical Exam (GOSCE) in breakout rooms in which each faculty member had 20 minutes to interact with the standardized patient (SP), with 5 minutes of feedback and 25 minutes of large group debriefing.

\subsubsection{University of Chicago}

The authors targeted GIM faculty who precept residents. Institutional support was attained and faculty were permitted to block 30 minutes of clinic time to attend a 90 minute training session during the lunch hour. Lunch and CME credit were provided. GOSCEs took place in actual clinic rooms and faculty used their personal logins, and quick text phrases on the desktop computers they normally use for patient care. Training consisted of a 20 minute lecture and 60 minute GOSCE in which each faculty member had 10 minutes to interact with the SP with 5 minutes of feedback and 10 minutes of large group debriefing (Table 1).

\subsection{Program Description}

In 2015, the authors adapted a student curriculum on patient-centered EHR use to meet the needs of faculty providers [20-22]. The faculty workshop consisted of a lecture and a GOSCE. The curriculum was based on best practices derived from a literature review, which was condensed into the 'HUMAN LEVEL' mnemonic to highlight key skills such as, "Honoring the golden minute" to ensure that the first minute of the visit is technology-free, and "Using the 'triangle of trust" to position the screen where the 
patient and provider can see it (Appendix 1) [20,22]. Direct observations (DOs) were used to assess the participants' patient-centered EHR use skills in clinical practice. Based on best practices, the authors developed and validated the electronic-Clinical Evaluation Exercise (e-CEX) instrument to assess patient-centered EHR use during DOs (Appendix 1) $[19,23]$. Faculty training was tailored to meet the demands of their clinical schedules, existing institutional infrastructure, and expectations for CME. The Institutional Review Boards at both institutions approved the study.

\subsubsection{Curricular Implementation}

The voluntary workshop targeted primary care faculty who precept students and residents in continuity clinics. The lecture reviewed how the EHR impacts patient-doctor communication and summarized best practices. During the GOSCE, faculty practiced their EHR-based communication skills with the SP by taking a focused history, reviewing data in the EHR, discussing assessment and plans, and documenting a portion of the visit (i.e., History of Present Illness or Assessment and Plan).

The SP received 4 hours of training to provide feedback on patient-centered EHR utilization. The GOSCE consisted of 3-4 faculty, 1 GOSCE facilitator (WL, MA, RF, Jl, or $\mathrm{MM}$ ) and $1 \mathrm{SP}$ per group. Faculty logged into the simulated $\mathrm{EHR}$, interacted with the SP, and received feedback from faculty peers, the GOSCE facilitator, and SP. The GOSCE depicted a straightforward diagnosis of acid reflux to allow participants to focus on their communication skills. 
Key resources in developing the GOSCE included institutional support to provide time and CME credit, and resources to train SPs. Both institutions used the EPIC EHR system (@ 2014, Epic Systems Corporation, Verona, Wisconsin), and the investigators partnered with EHR trainers to develop simulated charts in the training environment to mirror EHR use in actual patient care. Additional resources included access to internetenabled laptops or desktops with EHR software and access to clinic rooms for the GOSCEs.

\subsection{Program Evaluation}

\subsubsection{Post-Workshop Survey}

All participants received a 23 item post-workshop survey immediately after the session. Given limitations of faculty schedules, the survey enabled faculty to self-report postworkshop knowledge, attitude, and skills and asked them to retrospectively rate these domains pre-workshop. Responses to Likert items were dichotomized at the high end of the scale to denote agreement (i.e., agree/strongly agree). Descriptive statistics (i.e., mean [SD] or percentages) were used to summarize demographics and responses and two-sample t-tests, Wilcoxon rank-sum tests, or chi-square tests were used for comparisons between the two sites. Overall changes pre- vs. post-workshop were assessed using paired t-tests. Immediately following the training at both sites, feedback sessions were led by investigators (WWL and MLA) to assess for areas of strength and opportunities for improvement.

\subsubsection{Direct Observation}


Ten faculty ( 5 from CC and 5 from UC) were randomly selected to participate in direct observations (DO) while seeing real patients to assess EHR communication skills. Each of these ten faculty members had one twenty minute observation in their clinic pre-workshop and a second observation three months post-workshop.

The validated e-CEX tool was used to evaluate patient-centered EHR use during the direct observations and is based on the Accreditation Council for Graduate Medical Education's Mini CEX tool [23,36]. The e-CEX consists of 10 items related to best practices for patient-centered EHR use in the clinic setting identified from a systematic literature review and each item is scored on a 9 point Likert scale to assess a provider's EHR specific communication skills (Fig. 1) $[19,23]$. Behavioral anchors were used to define the behaviors associated with a particular score, for example for item 2 on the e-CEX assessing screen sharing, a rating of 1-3 was anchored as 'screen not visible to patient, provider's back to patient', 3-6 was anchored as "screen partly visible, occasionally with back to patient', and 6-9 was 'triangle set up optimal, verifies patient can see screen, faces patient.'

The first question from the e-CEX was excluded from the DO because it pertained to preparation for the visit outside the exam room; thus the 9 item tool had a maximum score of 81 points. Prior to the DOs, three faculty authors (WWL, MLA, MM) and two additional CC faculty members received a 2 hour training during which they individually watched standardized videos, used the e-CEX to rate performance, compared their 
ratings with an answer key, and came together to discuss discrepancies and address questions. Faculty e-CEX scores from pre- versus post-workshop DOs were compared using paired t-tests and repeated measures ANOVA. Comparison of pre-workshop scores between sites was performed using two-sample t-tests. Mean (SD) scores are reported.

3. Results

\subsection{Outcomes}

Thirty-two academic primary care faculty completed the voluntary workshop, consisting of 13 CC faculty (5 FM and 8 GIM) and 19 UC GIM faculty, and 94\% (30/32) completed the post-workshop evaluation. During feedback sessions, faculty reported the GOSCEs were the most valuable part of the workshop and allowed them to learn from observing peers.

\subsection{Post-Workshop Survey Results}

\section{Demographics:}

The majority $(63 \%, 19 / 30)$ of respondents were female (CC $50 \%$ vs. UC $72 \%, p=0.22$ ), with mean age of $46(S D=10)$ years (range 31-65) (CC 47 [SD=9] vs. UC 45 [SD=11], $\mathrm{p}=0.59$ ). Faculty at CC had more years of EHR experience with an average of 9.5 $(\mathrm{SD}=3.9)$ years vs. $5.7(\mathrm{SD}=6.2)$ at $\mathrm{UC}(\mathrm{p}=0.02)$.

\section{Participant Knowledge, Attitude and Skills}


All $(30 / 30,100 \%)$ faculty agreed it was 'important to receive training,' 'relevant to their practice,' and enabled them 'to better teach and role model patient-centered care for trainees,' with no difference in mean ratings between $\mathrm{CC}$ and $\mathrm{UC}$ faculty $(4.8$ [SD=0.5] vs. $4.7[S D=0.5], 4.6[S D=0.5]$ vs. $4.9[S D=0.3], 4.4[S D=0.5]$ vs. $4.5[S D=0.5], p>0.05$ for all). Importantly, 97\% (29/30) agreed that the workshop should be 'required for all health care providers' with no difference between $C C$ and UC (4.8 [SD $=0.5]$ vs. 4.6 $[S D=0.6], p=0.40)$.

When compared to retrospective recollections of pre-workshop knowledge, attitude and skills, there were significant post-workshop increases in mean scores of 'awareness of barriers' and 'knowledge of best practices' (pre vs. post; 3.7 [SD=1.1] vs. 4.5 [SD=0.8] and $3.1[S D=0.8]$ vs. $4.3[S D=0.5]$, respectively, $\mathrm{p}<0.001$ for both) with no site differences in the magnitude of these changes $(p=0.25$ and $p=0.92)$. Additionally, there was a significant post-workshop increase in mean ratings on ability to 'implement best practices' and 'teach trainees how to implement best practices' (3.3 [SD=0.6] vs. 4.2 $[S D=0.6]$ and $2.9[S D=0.7]$ vs. $4.1[S D=0.7]$, respectively, $p<0.001$ for both) with no site differences $(p=0.19$ and $p=0.17)$.

While almost all faculty (29/30, 97\%) agreed the GOSCE was an 'effective way to practice skills,' CC mean ratings were significantly higher than UC (4.6 [SD=0.5] vs. 4.2 $[S D=0.5], p=0.04)$. However, more UC faculty agreed the workshop was 'informative and effective' and that they 'gained new knowledge' (4.5 [SD=0.5] vs. 4.8 [SD=0.4], $\mathrm{p}=0.04$ and $4.2[\mathrm{SD}=0.6]$ vs. $4.7[\mathrm{SD}=0.5], \mathrm{p}=0.02)$. 


\subsection{Direct Observations Results}

The 9 items on the e-CEX were scored on a 9 point Likert scale. Ratings of 1-3 represent unsatisfactory performance, 4-6 represent satisfactory performance and 7-9 represent superior performance (Appendix 1). Overall, the mean pretraining scores ranged from 4.3 to 6.8 (Table 2). Pre-training, faculty were rated lowest on the following three skills: maintaining a conversational flow and explain what you are doing in the EHR (mean 4.0), encouraging patient interaction with the computer (mean 4.3) and optimal positioning for shared screen viewing (mean 4.6); while they were rated highest on maximizing eye contact and maintaining an open body language (mean 6.8), utilizing the EHR to promote individualized and collaborative care (mean 6.3) and proficiency in technology use, navigating EHR, typing etc. (mean 6.1).

When comparing overall pre- and post-workshop scores for the 10 faculty members, there was a significant increase in mean post-workshop total scores (pre 49.3 [SD=8.5] vs. post 62.8 [SD=10.3], $\mathrm{p}<0.001$; maximum total score 81 ) and all subjects had an improvement in total score between pre vs. post scores (mean change $=13.5[\mathrm{SD}=4.6]$, range 3-19). There was no significant difference between sites in the total pre-workshop scores or in the magnitude of the pre-post change (UC Pre 53.2 [SD=6.4] vs. CC Pre $45.4[S D=9.2], p=0.16 ; U C$ change $13.4[S D=6.2]$ vs. $C C$ change $13.6[S D=3.0]$, $\mathrm{p}=0.95)$. 
Faculty showed significant improvement one-month post-training on 7 of the 9 skills assessed by the e-CEX. Of these seven skills, the largest mean change was seen in the following, listed from largest to smallest change: (1) optimal positioning for shared screen viewing; (2) maintaining a conversational flow and explain what you are doing in the EHR; (3) encouraging patient interaction with the computer; (4) Integrating EHR use into natural flow of visit and integrating patient need; (5) honoring the golden minute and allowing patients to start with their concerns before introducing the computer; (6) proficiency in EHR use; and, (7) utilizing the EHR to promote individualized and collaborative care (Table 2). There was no significant change in maximizing eye contact/maintaining an open body language and effectively documenting notes in patient centered manner.

\section{Discussion and Conclusion}

\subsection{Discussion}

Our study demonstrated the feasibility and efficacy of implementing a short training and GOSCE to teach faculty how to use the EHR to promote patient-centered communication at two academic medical centers. We found that a 90-minute training was as effective as a 4-hour training and may be a feasible way to train faculty at other institutions. Faculty who were directly observed after the workshops were more likely to share the screen, demonstrate patient-centered body language, and use the EHR to promote patient-engagement and education compared to their pre-workshop performance. 
In the EHR era, providers must learn to improve their "computer-side" manner and find ways to nurture relationships with patients while managing the demands of the EHR. While other interventions like scribes, or improving the physical workspace may also help in improving patient-doctor-EHR communication, teaching EHR communication skills to providers is central to this initiative. Given the focus on patient experience in healthcare, and research showing improved outcomes with patient-centered communication strategies, implementing training in patient-centered EHR use should be a priority in medical education and continuing medical education. As institutions and health systems consider how to approach this issue, they may consider integrating key components of our workshop into institutionally mandated EHR training to ensure providers are being equipped to use the EHR as a communication- enhancing tool with their patients.

Our findings also suggest that specific EHR behaviors may be targeted for maximal impact of training. We found that providers retained and integrated several behaviors into their clinical practice three months after the training, including encouraging patient interaction with the EHR and starting the visit with the patient's concerns. Importantly, screen sharing improved significantly posttraining and studies exploring patient perceptions of EHR use found that they want transparency and patients identified screen sharing as an important communication building tool [21]. 
Our study also identified effective patient-centered documentation in the exam room as an area in need of further training. This is important to consider in the context of research showing that increasing EHR documentation burden and the resultant work-life interference has been linked to physician burnout [37-39]. Training providers to complete their documentation in the exam room while meaningfully interacting with their patients can improve patient satisfaction and physician quality of life by reducing the amount of EHR work they bring home at the end of the day. Furthermore, studies have shown that patients expressed dissatisfaction with physicians who did not engage the EHR to discuss their health or provide education and our short training showed that it is feasible to improve on these skills with a short intervention [21].

The patient-centered EHR use training and GOSCE is a novel and useful way for faculty to improve their EHR communication skills and better equips them to teach and rolemodel them with learners. Interestingly, despite the fact that faculty do not regularly participate in GOSCEs, they reported that the experience of watching their peers interact with the SP, and being able to observe some of their communication and workflow strategies, as well as receiving feedback from their peers was the most valuable part of the training and should be required for all providers.

Our study has several limitations. Our training was optional for faculty which introduces selection bias. In addition, while we included two sites in our study the study samples were small which limits our generalizability. Another potential 
limitation is that we were unable to collect a pre-survey on knowledge, attitude and skills and relied on the retrospective post-workshop survey which asked faculty to assess their knowledge, attitude and skills on patient centered EHR use prior to and after the training. As well, we were unable to conduct direct observations of all faculty pre and post training and relied on a sample of ten physicians to assess impact of the training on behaviors three months after the workshop. Lastly, the direct observations were not blinded to training status which may introduce bias.

We will continue to follow-up with faculty to assess for the durability of skills one year post- workshop and aim to assess patient satisfaction with faculty EHR communication. In addition, we will continue to train medical students and expand our training to include residents, subspecialty faculty, and allied health providers. Lastly, we will continue to test validity of the e-CEX tool for a variety of situations and learners.

There were some differences between the shorter and longer training. Faculty participating in the longer training reported somewhat higher GOSCE efficacy, which may be related to a longer amount of time allotted for the GOSCE in the 4 hour training. Interestingly, faculty who participated in the shorter workshop reported the training to be more informative and effective, which may be related to the UC faculty having fewer years of EHR experience compared with CC faculty. Despite these differences, faculty who participated in both versions of the training thought it was important and should be required. 


\subsection{Conclusion}

Faculty training is critical to the success of student and resident EHR curricula. In order to improve patient-centered EHR use during clinical encounters, faculty should be trained to teach, role-model and give feedback on these skills. The lecture and GOSCE provides a practical way to train busy faculty to implement EHR skills to enhance patient-doctor communication. As national standards for EHR training emerge, it will be important to ensure that both trainee and faculty training initiatives are included in the form of curricula and policies.

\subsection{Practice Implications:}

In summary, we found that a short lecture and GOSCE was an effective way to train faculty in patient-centered EHR use skills. Importantly, three months post-training, providers who participated in the workshop were found to have maintained improvements in their patient-centered EHR use skills in real clinical settings. The short 90 minute training is feasible to implement in busy academic practices and can be adapted for other clinical settings. Future work should assess the long-term integration of best practices, solicit feedback from patients on their provider's patient-centered EHR use skills and assess the faculty's ability to teach and give feedback on these skills to their learners. Faculty training on patient-centered EHR skills has the potential to enhance patient-doctor communication and promotes positive role modeling of these skills to learners. 


\section{Conflict of Interest}

The authors report no conflicts of interest.

\section{Acknowledgements}

Contributors: The authors wish to thank the University of Chicago's Medical Education Research, Innovation, Technology and Scholarship (MERITS) fellowship program, the Pritzker School of Medicine's Simulation Center, the Cleveland Clinic Simulation and Advanced Skills Center and Sandra Webb from the University of Chicago's Epic Training Center.

This work was supported by the Association of American Medical Colleges Central Group on Educational Affairs Collaborative Grant, the Arnold P. Gold Foundation Research on Humanistic Health Care Grant, the Picker Gold Graduate Medical Education Challenge Grant, the University of Chicago's Academy of Distinguished Medical Educators Grant, and the University of Chicago Bucksbaum Institute Pilot Grant.

Prior Presentations: This research was presented as oral presentations at the 2016 AAMC Medical Education Meeting in Seattle, WA on November 2016 and at the 2015 Society of General Internal Medicine (SGIM) Midwest Regional Meeting in Cleveland, $\mathrm{OH}$ on August 2015. 


\section{References}

1. Chaudhry B, Wang J, Wu S, Maglione M, Mojica W, Roth E, Morton SC, Shekelle PG. Systematic review: impact of health information technology on quality, efficiency, and costs of medical care. Ann Intern Med. 2006;144(10):742-52.

2. Hsu J, Huang J, Fung V, et al. Health information technology and physician-patient reactions: impact of computers on communication during outpatient primary care visits. J Am Med Inform Assoc. 2005;12:474-80.

3. Doyle RJ, Wang N, Anthony D, et al. Computers in the examination room and the electronic health record: physicians' perceived impact on clinical encounters before and after full installation and implementation. Fam Pract. 2012;5:601-8.

4. Ventres $\mathrm{W}$, Kooienga $\mathrm{S}$, Marlin $\mathrm{R}$, et al. Clinician style and examination room computers: a video ethnography. Fam Med. 2005;37(4):276-81.

5. Ventres W, Kooienga S, Vuckovic N, et al. Physicians, patients, and the electronic health record: an ethnographic analysis. Ann Fam Med. 2006;4(2):124-31.

6. Frankel R, Altschule Rr, George S, et al. Effects of exam-room computing on clinician-patient communication: A longitudinal qualitative study, J. Gen. Intern. Med. $2005 ; 20: 677-82$.

7. Margalit RS, Roter D, Dunevant MA, et al. Electronic medical record use and physician-patient communication: an observational study of Israeli primary care encounters. Patient Educ Couns. 2006;61(1):134-141.

8. Sinsky C, Colligan L, Li L, Prgomet M, Reynolds S, Goeders L, et al. Allocation of physician time in ambulatory practice: a time and motion study in 4 specialties. Ann Intern Med. 2016; 165(11):753-760. 
9. Yan C, Rose S, Rothberg MB, Mercer MB, Goodman K, Misra-Hebert AD. Physician, Scribe, and Patient Perspectives on Clinical Scribes in Primary Care. J Gen Intern Med. 2016; 31(9):990-5.

10. Reuben DB, Knudsen J, Senelick W, Glazier E, Koretz BK. The Effect of a Physician Partner Program on Physician Efficiency and Patient Satisfaction. JAMA Intern Med. 2014; 174(7):1190-3.

11. Imdieke BH, Martel ML. Integration of Medical Scribes in the Primary Care Setting: Improving Satisfaction. J Ambul Care Manage. 2017;40(1):17-25.

12. Kumarapeli $\mathrm{P}$, de Lusignan $\mathrm{S}$. Using the computer in the clinical consultation; setting the stage, reviewing, recording, and taking actions: multi-channel video study. J Am Med Inform Assoc. 2013;20(e1):e67-75.

13. Almquist JR, Kelly C, Bromberg J, et al. Consultation room design and the clinical encounter: the space and interaction randomized trial. HERD. 2009;3(1):41-78.

14. Levinson W, Roter DL, Mullooly JP, et al. Physician-patient communication. The relationship with malpractice claims among primary care physicians and surgeons. J Am Med Assoc. 1997;277 (7):553-559.

15. Makoul G, Curry RH, Tang PC. The use of electronic medical records: communication pat- terns in outpatient encounters. J Am Med Inform Assoc. $2001 ; 8(6): 610-5$.

16. Booth N, Robinson P, Kohannejad J. Identi cation of high-quality consultation practice in primary care: the effects of computer use on doctor-patient rapport. Inform Prim Care. 2004;12(2):75-83. 
17. Arar NH, Wen L, McGrath J, et al. Communicating about emotions during primary care out- patient visits: the role of electronic medical records. Inform Prim Care. $2005 ; 13(1): 13-22$.

18. Johnson KB, Serwint JR, Fagan LA, et al. Computer-based documentation: effects on patient-provider communication during pediatric health maintenance encounters. Pediatrics. 2008;122(3):509-8.

19. Alkureishi MA, Lee WW, Lyons M et al. , Impact of electronic medical record use on the patient-doctor relationship and communication: A systematic review. J. Gen. Intern. Med, 31 (2016) 548-60.

20. Alkureishi M, Lee WW, Farnan J, et al. Breaking away from the iPatient to care for the real patient: implementing a patient-centered EHR use curriculum. MedEdPORTAL Publications, 10 (2014) 9953.

21. Lee WW, Alkureishi MA, Ukabiala O et al. Patient perceptions of electronic medical record use by faculty and resident physicians: a mixed methods study, J. Gen. Intern. Med. 31 (2016) 1315-22.

22. Lee WW, Alkureishi ML, Wroblewski K, Farnan JM, Arora VM. Incorporating the human touch: Piloting a curriculum for patient-centered electronic health record use. Med Educ Online. 2017: 22(1): 1396171

23. Alkureishi MA, Lee WW, Lyons M, Wroblewski J, Farnan JM, Arora VM. Electronicclinical evaluation exercise (e-CEX): A new patient-centered EHR use tool. Patient Education and Counseling. 2017 Oct 10. Epub ahead of print: http://www.pecjournal.com/article/S0738-3991(17)30560-8/fulltext 
24. Ross S, Forgie S. Distracted doctoring: smartphones before patients? CMAJ. 2012;184(12):1440.

25. Shachak A, Reis S. The impact of electronic medical records on patient- doctor communication during consultation: a narrative literature review. J Eval Clin Pract. 2009;15(4):641-9.

26. McGrath JM, Arar NH, Pugh JA. The influence of electronic medical record usage on nonverbal communication in the medical interview. Health Informatics J. 2007;13 (2):105-18.

27. Saleem JJ, Flanagan ME, Russ AL, McMullen CK, Elli L, Russell SA, Bennett KJ, Matthias MS, Rehman SU, Schwartz MD, Frankel RM. You and me and the computer makes three: variations in exam room use of the electronic health record. J Am Med Inform Assoc. 2014;21(e1):e147-51.

28. Hirsch $\mathrm{O}$, Keller $\mathrm{H}$, Krones $\mathrm{T}$, Donner-Banzhoff $\mathrm{N}$. Arriba-lib: association of an evidence- based electronic library of decision aids with communication and decision-making in patients and primary care physicians. Int J Evid Based Healthc. $2012 ; 10(1): 68-76$

29. Furness ND, Bradford OJ, Paterson MP. Tablets in trauma: using mobile computing platforms to improve patient understanding and experience. Orthopedics. 2013;36(3):205-8.

30. Ventres WB, Frankel RM. Patient-centered care and electronic health records: it's still about the relation- ship. Fam Med. 2010; 42(5):364-366.

31. Pageler NM, Friedman CP, Longhurst CA. Refocusing medical education in the EHR Era. J Am Med Assoc. 2013; 310(21):2249-2250. 
32. Wald HS, George P, Rei TJS. Electronic health record training in undergraduate medical education: bridging theory to practice with curricula for empowering patientand relationship-centered care in the computerized setting. Acad Med. 2014;89(3):380-386.

33. Crampton $\mathrm{NH}$, Reis $\mathrm{S}$, Shachak A et. Al., Computers in the clinical encounter: a scoping review and thematic analysis, J. Am. Med. Inform. Assoc. 2016; 23(3):65465

34. Kazmi Z. Effects of exam room EHR use on doctor-patient communication: a systematic literature review, Inform. Prim. Care. 2013; 21(1):30-9.

35. Wuerth R, Campbell C, King WJ. Top 10 tips for effective use of electronic health records, Paediatr. Child Health. 2014; 19(3):138

36. Hauer KE. Enhancing feedback to students using the Mini-CEX. Acad Med. 2000; 75(5):524

37. Babbott S, Manwell LB, Brown R, et al. Electronic medical records and physician stress in primary care: results from the MEMO Study. J Am Med Inform Assoc. 2014;21(e1): e100-106.

38. Friedberg MW, Chen PG, Van Busum KR, et al. Research report: factors affecting physician professional satisfaction and their implications for patient care, health systems, and health policy. Santa Monica, CA: Rand Corporation, 2013.

39. Arndt BG, Beasley JW, Watkinson MD et al. Tethered to the EHR: Primary Care Physician Workload Assessment Using EHR Event Log Data and Time-Motion Observations. Ann Fam Med. 2017; (15) 5: 419-426. 
Table 1: Comparison of Training at Cleveland Clinic and University of Chicago

\begin{tabular}{|l|l|l|}
\hline & Cleveland Clinic & University of Chicago \\
\hline Lecture & $75 \mathrm{~min}$ & $25 \mathrm{~min}$ \\
\hline GOSCE & $100 \mathrm{~min}$ & $60 \mathrm{~min}$ \\
\hline Session Feedback & $25 \mathrm{~min}$ & $10 \mathrm{~min}$ \\
\hline Total Time & $240 \mathrm{~min}$ & $90 \mathrm{~min}$ \\
\hline Setting & Conference Room & Clinic Rooms \\
\hline Computer & Laptops & Clinic desktop \\
\hline
\end{tabular}


Table 2: Comparison of Direct Observation Pre and Post Workshop using e-CEX Tool

\begin{tabular}{|l|l|l|l|l|}
\hline & $\begin{array}{l}\text { Pre- } \\
\text { Workshop }\end{array}$ & $\begin{array}{l}\text { Post- } \\
\text { Workshop }\end{array}$ & $\begin{array}{l}\text { Mean } \\
\text { Change } \\
\text { (Post-Pre) }\end{array}$ & P value \\
\hline $\begin{array}{l}\text { Overall Total Score (n=10) } \\
\text { CC (n=5) }\end{array}$ & $\begin{array}{l}49.3(8.5) \\
45.4(9.2)\end{array}$ & $\begin{array}{l}62.8(10.3) \\
59.0(8.9) \\
63.6(11.1)\end{array}$ & $\begin{array}{l}13.5(4.6) \\
13.6(3.0) \\
13.4(6.2)\end{array}$ & $<0.001$ \\
\hline $\begin{array}{l}\text { e-CEX question } \\
53.2(6.4)\end{array}$ & 66.6 & $2.5(1.3)$ & $<0.001$ \\
\hline $\begin{array}{l}\text { 2. Arrange provider, patient, and } \\
\text { computer screen in a 'triangle of } \\
\text { trust' to allow shared viewing }\end{array}$ & $4.6(1.3)$ & $7.1(1.2)$ & 0.01 \\
\hline $\begin{array}{l}\text { 3. Honor the Golden Minute. Allow } \\
\text { patient to start with their concerns }\end{array}$ & $5.6(1.4)$ & $7.2(1.5)$ & $1.6(1.5)$ & 0.01 \\
\hline $\begin{array}{l}\text { 4. While maintaining conversational } \\
\text { flow, explain actions with EHR }\end{array}$ & $4.0(2.1)$ & $6.5(1.5)$ & $2.5(1.9)$ & 0.002 \\
\hline $\begin{array}{l}\text { 5. Use EHR in natural flow of visit } \\
\text { and integrate patient needs. } \\
\text { Disengage during sensitive } \\
\text { discussions }\end{array}$ & $5.7(1.6)$ & $7.3(1.2)$ & $1.6(1.2)$ & 0.002 \\
\hline $\begin{array}{l}\text { 6. Maximize eye contact, open body } \\
\text { language, and other nonverbal } \\
\text { actions to convey listening and } \\
\text { understanding }\end{array}$ & $6.8(0.9)$ & $7.4(1.2)$ & $0.6(1.2)$ & 0.14 \\
\hline $\begin{array}{l}\text { 7. Encourage patient interaction with } \\
\text { technology by showing results etc. } \\
\text { while explaining \& discussing care }\end{array}$ & $4.3(1.9)$ & $6.4(1.8)$ & $2.1(1.0)$ & $<0.001$ \\
\hline $\begin{array}{l}\text { 8. Proficient in technology use. } \\
\text { Adept typist, easily navigates EHR } \\
\text { screens and tabs to facilitate flow of } \\
\text { visit. Logs off at end of visit. }\end{array}$ & $6.1(1.5)$ & $7.3(1.9)$ & $1.2(1.0)$ & 0.01 \\
\hline
\end{tabular}




\begin{tabular}{|l|l|l|l|l|}
\hline $\begin{array}{l}\text { 9. While integrating EHR into clinic } \\
\text { visit, effectively documents note. }\end{array}$ & $5.9(1.3)$ & $6.3(1.5)$ & $0.4(0.8)$ & 0.17 \\
\hline $\begin{array}{l}\text { 10. Utilizes EHR to promote } \\
\text { individualized and collaborative care. }\end{array}$ & $6.3(1.3)$ & $7.3(1.3)$ & $1.0(1.2)$ & 0.03 \\
\hline
\end{tabular}

Values in table are mean (SD). $\mathrm{P}$ values are from paired t-tests. 